\title{
Prática do espaço, experiência do corpo: Sennett e a cidade
}

Marta Mega de Andrade

Departamento de História, Instituto de Filosofia e Ciências Humanas/Universidade Federal do Rio de Janeiro*
Richard Sennett. Flesch and stone: the body and the city in Western civilization. London: Faber \& Faber, 1994.

A cidade, para o sociólogo Richard Sennett, sempre esteve no cerne de suas preocupações. São testemunhos disso, desde a coletânea que organizou em 1969 (Classic essays on the culture of cities), até The conscience of the eye: the design and social life of cities, em 1990, sem esquecer o clássico The fall of public man (1974), em que a cidade é examinada segundo o crivo da vida cívica.

Em Flesch and stone: the body and the city in Western civilization, Sennett retoma, com mais força, temas e abordagens que não são propriamente - inéditos em sua obra, mas se apresentam aqui concentrados para trazer à tona - espaço social que produz a própria cidade. Ao constatar que a prática do espaço urbano no mundo contemporâneo promove o individualismo e o apaziguamento dos encontros corporais, ele sugere que a história da cidade, tecida pela experiência corporal das pessoas (p. 15), pode trazer luz para melhor compreender a situação atual.

Este enfoque nos atrai a atenção sob vários aspectos, mas em especial por incidir sobre corpo e cidade, ao pontuar uma história da produção do espaço urbano no Ocidente a partir da experiência (humana) corporalmente expressada/mobilizada. Uma história tão bizarra quanto sua narrativa, que não privilegia tipos de fontes, nem pretende traçar o começo, o meio e o fim. $\bigcirc \cdots$
*A autora é bolsista de Doutoramento da FAPESP e este ensaio se desenvolveu no quadro dos serninários da disciplina "Fontes materiais para a pesquisa histórica", ministrado em 1996 pelo Prof. Ulpiano T. Bezerra de Meneses no curso de pós-graduaçào em História Social, FFLCH/USP. 
espanto que está em seu ponto de partida - o de que numa "civilização" como a do ocidente contemporâneo, em que o corpo é supervalorizado, sexualizado, sobrecarregado de sentido, a experiência sensorial tenda a ser neutralizada, pacificada pela mobilidade e desqualificação do espaço - modula as estratégias de abordagem de Richard Sennett, nos diversos "casos" estudados: à pergunta geral sobre que processo histórico gerou para os ocidentais uma tal configuração da relação carne-pedra, respondem cidades e momentos tão específicos quanto a Paris de Jehan de Chelles, ou a Londres de E. M. Forster. Estes casos singulares, descontínuos, se conectam pela perspectiva do estudo: a forma como se concebe, e se percebe o corpo, como se age com o corpo e se sofre através do corpo e dos sentidos é uma experiência primeira de produção da cidade. Isto é mais do que uma questão de simetria entre, suponhamos, planejamento urbano e concepção do corpo. O tema é bem mais complexo, e demanda uma reflexão sobre a espacialidade das interações sociais, sobre a dimensão do corpo (da carne, cujo sentido é bem mais estrito) na formação da individualidade (e da subjetividade), e ainda sobre a compreensão mesma do sentido de experiência . Se, enfim, conseguimos avaliar o modo como o individualismo moderno se enraizou pode ser compreendido no ato de recostar-se em uma confortável poltrona na Londres do século XIX (Urban individuailism, p.340-42, ver neste ensaio, mais adiante, p.306), ou a crise da cidadania ateniense do conflito entre o espaço cívico e a exposição (nudez) do corpo entre o Vo e o № séculos a.C (Nakedness, p.31-67), teremos estabelecido o lugar de direito da obra Flesch and stone no campo da história da cultura material, no mesmo movimento em que colocamos em debate a dimensão material da vida social.

\section{I. $O$ "grande" e o "pequeno"}

Não se pode negar que alguns termos como "civilização ocidental", "individualismo moderno", tanto quanto alguns temas como a "Atenas de Péricles" e a "Revolução Francesa", imprimem à obra um sentido globalizante, uma linha de desenvolvimento que "salta" entre períodos históricos carregados de sentido e de valor, alguns dos quais podem se chamar paradigmáticos. Sennett explica:

"I have written this history (...) by making studies of individual cities at specific moments - moments when the outbreak of a war or revolution, the inauguration of a building, the announcement of a medical discovery, or the publication of a book marked a significant relation between people's experience of their own bodies and the spaces in which they lived" (p.22).

"salto" entre os grandes eventos é justificado, pois, dentro de uma estratégia de abordagem que visa uma história mais localizada, focalizada no ponto de encontro entre carne e pedra. Assim, por exemplo, a descoberta dos mecanismos da circulação do sangue por Harvey, além de marcar a inauguração de uma nova abordagem científica do corpo humano como organismo, testemunha uma nova concepção da relação corpo-espaço: a cidade deve promover a circulação e a mobilidade do corpo; os fluxos (de pessoas, de água, de ar, eic) devem ser regulados em nome da salubridade (Moving bodies, p.25581). Mas na dimensão da experiência sensorial em seu encontro com o espaço 
habitado, não se trata de reproduzir, em forma de injunção, um saber sobre o corpo e uma "adequação" ao espaço, mas de confrontar, na carne e na pedra, esta forma de representação. $O$ resultado do confronto são práticas espaciais, experiências sensoriais tão globais quanto as concepções de corpo e de espaço que sobre elas incidem, mas que ao modificarem a vivência do espaço urbano ao nível do uso, das formas de apropriação deste espaço, são elas próprias capazes de promover, de atuar, projetando uma nova compreensão de si na direção do individualismo leste é o sentido da terceira parte de Flesch and stone: arteries and veins, p.255-377).

A "carne" e a "pedra" traduzem, como nexos de um encontro, um horizonte de historicidade que, justamente por ser material ao extremo, não pode ser somente objetivo. O apelo constante na obra de Richard Sennett ao modo como se experimenta corporalmente a cidade, é ainda uma requisição do "fazer falar" as vivências do espaço urbano. Neste sentido, o testemunho de escritos literários, científicos, os planejamentos de arquitetos e construtores, as obras de arte, conferem a Sennett a oportunidade de lidar com os indícios na escrita, no planejamento, na iconografia, da expréssão de experiências dos sentidos; o discurso emerge como experiência dada no insterstício, no mútuo choque de carne e pedra.

Desta maneira, Sennett observa na Paris de Jehan de Chelles (século XIII) e Humbert de Romans (século XIV), o conflito entre as práticas antitéticas de corpo e espaço exigidas, de um lado, pela religião, e, de outro lado, pelas atividades do comerciante.

\footnotetext{
"Economic time unfolded by following up opportunities, taking advantage of unforeseen events. Economics prompted a conjunction of functional use of space and opportunistic use of time. Christian time, by confrast, was founded on the story of Jesus own life, a history people knew by heart. Religion prompted emotional attachment to place coupled with a sense of narrative time, a narrative fixed and certain" (Each man is a devil to himself, p. 1881.
}

O resultado deste conflito aparece matizado em obras de arte, que ele aponta, como A procissão do Calvário (Pieter Brueghel, o Velho), Flagelo (Piero della Francesca), e Paisagem com a queda de lcaro (Pieter Brueghel). Um espaço duplo de compaixão e negociação, uma paisagem de apaziguamento que afasta o drama do estranhamento, anunciam de forma bizarra que a comunidade "livre" onde se compadece com a situação dos outros afasta, para isso, o "Outro" que não tem lugar, o forasteiro, o judeu dos guetos de Veneza (Each man is a devil to himself, p.207-1 11. A ligação cristã à cidade, expressa pelo princípio da Imitação de Cristo, nas instituições de caridade, hospitais, etc., e nos jardins "melancólicos" de mosteiros e igrejas, depende desse apaziguamento com relação à agressividade cotidiana de uma atividade que já coloca o espaço como caminho, circuito indiferenciado de um mercado a outro.

A experiência singular postula, aqui, como em outros capítulos do livro, a dimensão subjetiva na história do "lugar". Em um trecho de l'invention du quotidien, Michel De Certeau (1990) interpreta esta dimensão individual e subjetiva nas práticas de espaço, afirmando que cada individualidade "é o lugar onde atua uma pluralidade incoerente (e freqüentemente contraditória) de suas 
determinações relacionais". Isto não significa apenas - e creio que isto se aplica ao estudo de Sennett - que a individualidade é socialmente determinada, mas simplesmente que há uma dimensão na história social, em que o indivíduo que se expressa em discursos, em práticas, imprime no tempo e no espaço sociais texturas compartilhadas, comportamentos re-produzidos, concepções herdadas, no encontro do corpo e da pedra.

Prática e experiência, concepção e vivência, individual e social, espaço e tempo, são os desafios lançados à dimensão do "pequeno". Esta "micro-história" afirma, por suas estratégias, que nas relações estabelecidas corriqueiramente entre o indivíduo praticante e o espaço, ałua uma dimensão produtora, e não simplesmente reflexiva ou repetidora. A sua maneira, carne e pedra produzem corpo e espaço, formas de interação social e vias de transformação histórica de uma sociedade ou de uma cultura.

Podemos supor da parte de Richard Sennett uma aproximação não explícita com o horizonte das invenções do cotidiano (De Certeau 1990)? Embora a preocupação em definir a relação entre a vida cotidiana e a experiência do espaço nấo esteja diretamente presente em Flesch and stone, pode-se discutir se uma reflexão sobre o conceito de cotidiano não seria fundamental para esclarecer o lugar, o tempo, a implicação social daquilo que se vem denominando o "pequeno". A familiaridade entre a percepção do "dia-a-dia" e os acontecimentos repetitivos, pequenos, corriqueiros, pode ser encontrada tanto em Platão (Leis) quanto na grande obra de Fernand Braudel - Civilisation matérielle et capitalisme (1967). A melhor visualização do cotidiano como dimensão da história social pode nos auxiliar a compreender que o "pequeno" não é um microcosmo que acompanha o "grande", as transformações gerais. Fernand Braudel inaugurou a defesa teórica dos cortes na duração da história; mostrou que os "tempos" sociais eram múltiplos e não lineares. Conectou à defesa dos "cortes temporais" uma interpretação dos "níveis" de transformação: dos acontecimentos políticos, ao fluxos da economia, e às estruturas do cotidiano. Podemos dizer que o que há de comum na busca da definição de um conceito de cotidiano é a apresentação da dimensão cotidiana como modo da vida social, espaço e tempo próprios de produção, reprodução, uso, experiência. E todas as expressões que incorporam a história contada por Richard Sennett em Flesch and stone, são de algum modo parte integrante da discussão da dimensão histórica do cotidiano social la prática e a experiência, os sentidos e o corpo, espaço e lugar, artefato, indivíduol.

Um exemplo: a Alenas de Péricles

O primeiro capítulo de Flesch and stone, "Nakedness" (p.31-67), deve ser mencionado, ao se propor uma conclusão sobre o "global" e o "local" na história do corpo e da cidade. Neste capítulo, Sennett parte do ideal expresso na oração fúnebre de Péricles (em Tucidides, História da Guerra do Peloponeso, II, XXXIV-XIVII; ideal de unidade entre palavras e feitos, para discutir a experiência corporal do espaço da cidade em Atenas

Percebe-se a partir dessa experiência, uma apropriação de lugares modulada pelas concepções ligadas ao gênero (masculino/feminino). A fisiologia 
do calor do corpo regia a concepção do corpo humano, criando um continuum entre masculino e feminino, o primeiro quente e ativo, o segundo frio e passivo. O espaço podia, assim, comportar uma adequação "natural" em acordo com o gênero: às mulheres, o abrigo do interior da casa; aos homens, a exposição ao espaço aberto e público da cidade (Xenofonte, Econômico, VII-X). Mas ao dizer que o espaço doméstico, assim como o espaço público, tinha gênero na concepção dos atenienses, Sennett estaria afirmando que a mulher ficava restrita ao espaço privado? Se tal resposta pudesse ser afirmativa no contexto da análise de Sennett, esta análise se enfraqueceria pelas evidências de que não era assim, principalmente entre as classes mais baixas em Atenas. Com efeito, dizer que o espaço doméstico era feminino para os atenienses, deve ter para nós, como para o autor, outras implicações: parte-se de uma experiência social do espaço, em que a compreensão do corpo regulava a apropriação de lugares, e ainda justificava, segundo a natureza, uma relação de dominação, de subordinação da mulher ao homem. Não se trata de questionar a "ubiqüidade da mulher", mas as implicações historiográficas e sociais da afirmação de que um artefato, como o espaço, pode ter gênero.

A prática da homossexualidade é uma outra problemática focalizada por Sennett, como exercício de exposição do corpo masculino, do córpo ativo e, por isso, um exercício corporal para a cidadania. $O$ ideal de exposição da face, do corpo, das palavras, era constituinte da experiência da cidadania democrática ateniense. Portanto, na exposição da nudez nos ginásios, no jogo de honra e dignidade proposto pelas relações homossexuais, se aprendia a ser cidadão e a amar, literalmente, a cidade (ver, por ex., a insistência de Aristófanes em termos derivados de erotés, para designar a ligação do ateniense à cidadel: a mais perfeita unidade de palavras e atos, de indivíduos e pólis, podia se expressar, e se apreender, nos espaços de encontro entre erastés e eromenos. Mas se a palavra grega para cidade, a pólis, "meant far more to an Athenian like Pericles than a place on the map; it meant the place where people achieved unity" (p.38-9), pode-se propor uma reflexão sobre uma afirmação comum entre os gregos antigos, assim como entre muitos estudiosos modernos da Grécia Antiga (como Loraux 1990): a de que "Atenas são os atenienses". Por muito tempo tem-se tomado esta afirmação como um modo de dizer que a originalidade da cidade grega era a de ser uma entidade política, uma comunidade "espiritual" entre os indivíduos-cidadãos. Com isso, o espaço da cidade grega se designaria significativamente por "espaço cívico", carregado de sentido comunitário, religioso, moral. Esta originalidade explicaria, por exemplo, por que Esparta, que nunca se constituiu como espaço urbano no sentido em que o compreendemos - de atividades tipicamente urbanas (Austin \& Vidal-Naquet 1972) - era considerada uma pólis. Sem contradizer esta forma de ver a pólis grega, que certamente marcava a experiência de comunidade dos gregos antigos, como retornar ao espaço urbano, à cidade como espaço de práticas? Essa identificação dos cidadãos com a pólis efetivamente "apagava" a cidade, - espaço urbano? Ou derivava de uma prática particular deste espaço, assim como de uma experiência particular de corpo "dos atenienses"?

Se podemos então falar de uma unidade desejada entre as práticas no espaço urbano e a experiência do corpo, esta mesma unidade, na 
experiência da cidadania, fragmentava-se no espaço urbano, mais precisamente no espaço político. A força do corpo nu, exposto e ereto (orthós) inspirava a construção de espaços como o Párthenon (feito para se ver externamente), como os pórticos da ágora. Mas este mesmo corpo cidadão, em sua exposição, arriscava-se a não conseguir conter seu calor nos debates políticos, nas representações teatrais, etc. Diante da prática espacial do cidadão no espaço público lágora, Pnyx, Bouleutérion, Heliéia, teatrol, o corpo se expunha ao sofrimento no espaço: a hýbris, o calor das palavras, o drama, arrebatavam o indivíduo sentado, posição passiva própria à amplificação do páthos (F. Zeitlin 1990). Em outras palavras: se o encontro carne-pedra promovia a produção do espaço urbano em acordo com as concepções sobre o corpo, na vivência deste espaço era preciso lidar com a virtualidade da dissolução do ideal pelas formas de agir no espaço público.

\footnotetext{
"The master image of bodily power did not create civic unity: the code of sexuality affirming equality, harmony, and mutual integrity could not be recreated in politics. The citizen's body in its political posture was instead nakedly exposed to the powers of the voice in the same way we sometimes speak of someone who is naked as defenseless. From this political duality arose the seated 'páthos' of which Froma Zeiltin writes: the páthos of experiencing the heat of passion in a passive body" (p.06).
}

As conclusões a que chega o autor poderiam levar a um amplo questionamento da cidadania e da participação política em Atenas sob a perspectiva das práticas de espaço. Mas o próprio Sennett apenas sugere uma tal possibilidade, preferindo frisar a diferença de uma experiência antiga do corpo e do espaço, em que o corpo pertence à cidade, molda-se para a cidade e se regula pelos espaços da cidade, com relação ao individualismo moderno. Uma experiência que, apesar do desejo de unidade de palavras e atos, de corpo e pedra, valoriza a capacidade de sofrimento do corpo (páthos), isto é, a positividade do despertar do corpo pela pedra.

É preciso completar: o estudo da cidade dos atenienses por Sennett tomou deliberadamente a perspectiva da pólis como espaço político, e neste sentido a divisão geral entre espaço público e espaço doméstico, e a categorização social entre cidadãos (homens e mutheres), metecos, escravos. Seria bastante interessante uma proposta de ampliação das questões formuladas por Sennett, tomando-se a perspectiva da cidade como "lugar de habitação", e interpretando as categorias sociais nas formas de praticar o espaço, isto é, de habitar. Observar, então, que relações se configurariam entre o local e o global, entre o "grande" e o "pequeno".

\section{Modos de fazer}

Na dimensão da carne e da pedra, não é possivel visualizar um processo social de apropriação e transformação se não se considerar, para além do objeto, os modos de uso. Termos recorrentes na obra de Sennett, como experiência ou vivência, têm o fundamento de sua inteligibilidade comprometido se não se considerar a dimensão do uso na formação da própria experiência. Chamo a atenção mais uma vez para as invenções do cotidiano, tal como Michel 
De Certeau (1990) nos propunha: artes de fazer. Práticas e concepções de espaço e lugar, nem sempre previstas pelas atitudes dominantes diante do corpo e do espaço, mas determinantes para as transformações nessa própria ligação da carne à pedra, aparecem no uso, e não somente na produção.

Neste ponto, devemos considerar as críticas que tanto Sennett quanto Michel De Certeau fazem a Michel Foucault (mais precisamente referindo-se a Surveiller et punir, 19751, já que elas são esclarecedoras da perspectiva em que se colocam, para ambos, os modos de fazer como possibilidades para a criação de configurações inesperadas do espaço. Ambos afirmam a capacidade de resistência e criação do uso, em contraposição ao que entendem ser a passividade do corpo com relação ao espaço desenhado pelos projetistas, esquadrinhado pelas relações de poder, reproduzindo concepções dominantes, focalizado tanto por Surveiller et punir quanto por outras obras de M. Foucault. Mas quando se trata da abordagem de Foucault, é preciso reformular tanto a questão do poder, quanto a da resistência e criatividade. Para este último caso, remeto ao pequeno texto sobre a rebelião no Irã Inutile de se soulever? (Foucault 19791, acreditando que a questão da resistência muda de perspectiva na compreensão do poder que permeia a obra de Michel Foucault: primariamente como exercício de criação, e apenas restritamente (em sua formulação jurídica) como ato de destruição ou domínio. Deve-se antes compreender e colocar em causa este poder como exercício que $M$. Foucault propõe (1978), para depois discutir se os corpos sobre os quais incidem as práticas penais, por exemplo, são "passivos".

A concepção da atividade do corpo na experiência do espaço, em Michel De Certeau e Richard Sennett, parte de uma aceitação de que as relações de poder são relações sociais de dominação; e que contra esta dominação, que certamente produz espaços e corpos de acordo com determinadas práticas e saberes dominantes, a prática cotidiana impõe sua inventividade. Se este é o ponto de vista de Michel De Certeau, podemos seguramente afirmar a vizinhança entre esta perspectiva e a de Sennett, pois somente se imaginamos as experiências da carne e da pedra em seu encontro na dimensão do cotidiano, temos condições de afirmar a "carne" e a "pedra" como agentes históricos, agentes de transformação histórica.

O exemplo do estudo sobre os guetos de Veneza é um daqueles aos quais podemos nos referir (Fear or touching, p.212-53). De acordo com Sennett, esses guetos da Veneza do século XVI foram criados dentro do mesmo conflito que presidia à justaposição de uma atividade mercantil a uma comunidade cristã, acima mencionada. Veneza, como grande centro de comércio, constituía-se como morada, ponto de partida e chegada de estrangeiros de todas as partes, entre eles os judeus. Este fluxo de estrangeiros acompanhava-se de um receio do outro pela comunidade cristã: males como doenças ou derrotas em disputas bélicas eram imputados à contaminação da cidade pelo estrangeiro, principalmente residente. Os guetos representavam uma forma de segregação, favorecida, de resto, pela geografia de Veneza. E os corpos dos judeus eram estigmatizados com o medo do toque, o temor mesmo da proximidade.

A segregação acoplava-se quer à tolerância, quer à repressão, conforme a necessidade da comunidade cristã. Mas de um certo modo, o gueto 
protegia os judeus dos ataques, deixando a eles, dentro do espaço cercado, liberdade para seus próprios costumes e para seu culto. Disto derivava a formação de uma identidade de grupo, fortalecendo o sentido coletivo da comunidade judaica reunida, transformando o espaço da segregação em espaço apropriado pelos judeus. Por certo, essa identidade advinha da necessidade de auto-afirmação e defesa, com relação às táłicas de segregação no espaço e marcação dos corpos, levadas a cabo pelos cristãos. Eram, como diz Sennett, um escudo, mais que uma espada.

Com isto não se pode concluir que esta identidade advinha da passividade, entendida como adaptação a uma situação imposta. Utilizo o termo apropriação para marcar aquilo que as análises de Sennett deixam transparecer: que 0 modo de construção dessa identidade encontrava-se profundamente relacionado ao modo como os próprios judeus usavam as condições espaciais que thes eram impostas, de alguma forma produzindo mais do que essas condições. Trata-se, pois, de uma situação dinâmica, em que no encontro cotidiano entre a comunidade e a segregação, entre os estrangeiros e a suspeita, entre os judeus e a opressão, uma produção de espaço se determinava, uma experiência sensorial se produzia, e os liames da identidade se forjavam e se repetiam. Um dos caminhos do uso do espaço nos leva, pois, em direção aos mecanismos de afirmação de uma identidade de grupo.

No capitulo intitulado The cloak of darkness (p.68-86), surge com relativa importância a definição de um fenômeno social capaz de agenciar práticas corporais e espaciais como modos de subverter ou converter a "ordem vigente". Trata-se dos rituais, mais precisamente das Tesmofórias e das Adônias, celebrações femininas da antiga pólis ateniense. Ambos os rituais faziam uso do espaço urbano, jogando com a sexualidade no corpo feminino. Mas as Tesmofórias constituíam-se como festas do calendário oficial, e envolviam a comunidade como um todo na medida em que incidiam sobre uma mitologia da vida e da morte na reprodução e no tempo; as Adônias, pelo contrário, eram festas suspeitas, particulares, e apenas toleradas. De acordo com Sennett, os dois festejos, cada um de modo particular, promoviam uma certa transmutação da opressão em liberdade, transmutação operada pelo espaço e pelo corpo.

As Tesmofórias ocorriam no outono em Atenas, quando grupos de mulheres casadas passavam dias celebrando ritos sem sair de dentro de buracos escavados, onde carcaças de porcos cheias de grãos apodreciam. Ao cheiro nauseante se juntavam plantas antiafrodisíacas como o salgueiro e a alface. Alguns testemunhos, como o da peça Tesmofórias, de Aristófanes, nos sugerem que os rituais eram envoltos em mistérios vedados aos homens, e também que uma característica importante dessas celebrações era a de conferir às mulheres de Atenas um grau de participação próximo ao político e à cidadania (ver Tesmofórias, v. 350-70). R. Sennett aponta uma possível confirmação deste fato, evocando testemunhos da arqueologia que sugerem a escavação de buracos para a celebração das Tesmofórias na colina da Pnyx (p.72). No espaço urbano, as Tesmofórias tinham seu sentido reinventado: de um rito agrário ligado à terra, passava-se a um rito de fertilidade humana acentuando o jogo entre o desejo e a abstinência sexual. De certa forma, os rituais que ficavam sob a responsabilidade de mulheres casadas e filhas legítimas conferiam uma dignidade ao corpo frio e 
ao silêncio feminino, celebrando mistérios que só esses corpos podiam celebrar: o drama da descida ao Hades, lugar escuro e úmido das potências da morte, e das lamentações por Perséfone, filha de Deméter. Esta dignidade, Sennett afirma, era produzida no corpo feminino pelas maneiras de usar o espaço que o ritual promovia:

"The cloak of darkness in the earth, the cold of the pits, the closeness to death, transformed the status of their bodies. The women made a journey during the Thesmophoria through darkness, emerging into the light, their dignity affirmed" (p.72).

As Adônias envolviam de outra maneira as mulheres em Atenas. Tratava-se de uma festividade não-oficial e, de resto, bastante mal vista, envolvendo provavelmente mulheres à margem dos estatutos de legitimidade, como as concubinas e hetaíras. Celebrava-se o drama de Adonis, figura mitológica relacionada aos tà aphrodísia, particularmente ao desejo sexual feminino. As Adônias tinham lugar no alıo verão, e eram inauguradas pela disposição de sementeiras de alface no telhado das casas afim de que o sol a pino apodrecesse os brotos da planta. Em torno desses brotos mortos antes de seu pleno desenvolvimento, as mulheres celebravam à noite, queimando plantas odoríicas como a mirra, cantando, dançando, conversando ao abrigo dos olhares pela escuridão da noite nas ruelas residenciais de Atenas. Para que tais celebrações entre mulheres acontecesse, o terraço das casas, espaço habitualmente sem uso, era transformado em lugar da cerimônia, lugar das mulheres. Se no caso das Tesmofórias a dignidade das mulheres era afirmada por certos procedimentos espaciais plenos de sentido mitológico, que valorizavam as características de seu corpo frio (descer nos fossos cavados e escuros, e depois emergir para a luz do dia próximo à Pnyx), nas Adônias as mulheres usavam para elas mesmas um espaço pouco marcado pelos valores sociais do dentro e do fora, do frio e do quente, etc. Em outras palavras, um espaço cujo uso era deixado "em aberto", fazendo assim pouco sentido para um observador externo. Neste espaço, protegidas pelo escuro da noite, as mulheres conquistavam liberdade na conversa, recuperando assim, segundo Sennett, o poder da palavra. Falavam sobre seus próprios desejos? Os antigos, Platão, por exemplo, sugeriam que fosse assim em relação a palavras e atos.

Ritual é o termo que sintetiza as formas da transmutação do gênero feminino, do significado social negativo ao positivo, no caso das Tesmofórias, e dos espaços restritos, e do silêncio adequado, à fala obscura em um espaço sem sentido, por isso mesmo positivo para a afirmação da alteridade do gênero feminino, no caso das Adônias. Para R. Sennett,

"Ritual is one way the oppressed - men as well as women - can respond to the slights and contempt otherwise suffer in society, and ritual more generally can make the pains of living and dying bearable. Ritual constifutes the social form in which human beings seek to deal with denial as active agents, rather than as passive viclims" (p. 80).

No contexto de um questionamento sobre os "modos de fazer", as práticas rituais têm o seu lugar. Mas o que Sennett propõe, ao abordar o ritual em Atenas, é que, em primeiro lugar, a civilização ocidental perdeu o sentido desta prática ao neutralizar o encontro com o espaço na atividade do corpo; em segundo 
lugar, que a posição fundamental do ritual nas sociedades antigas ou arcaicas demonstra precisamente uma forma de lidar com o sofrimento da coletividade como um todo, ou de grupos sociais, compreendendo a positividade deste sofrimento, e transformando-o assim, de alguma forma, em significados sociais, quer relativos à coesão do grupo, quer à sua reprodução, ou mesmo à liberdade do "oprimido", como no caso das Adônias. Uma forma positiva de afirmar-se, que necessita apoiar-se numa experiência da conexão entre corpo e espaço.

Aquilo que tanto Michel De Certeau quanto Sennett viram, nas práticas espaciais ou no ritual, é que essas práticas não carecem de explicação. Entre os ritos, para Sennett, entre as práticas, para De Certeau, e o lógos, há um desencontro: os rituais não precisam ser discutidos, e, se o são, deixam de poder operar como rituais. De Certeau fala de um campo de estratégias e táticas silenciosas, cuịa compreensão está mais próxima da experiência grega da métis do que do paradigma semântico da lingüística (1990: 1 18-35). Dessa experiência que, segundo os estudos de J-P. Vernant e M. Detienne (1976), incidia (no período clássico) sobre as atividades humanas que exigiam uma razão prática, um raciocínio ardiloso e de ocasião: a caça, a pesca, etc. $O$ silêncio e o não totalmente concebido são características básicas dos modos de fazer. De fato, defrontamo-nos neste ponto com o "bizarro" da proposta de Sennett: como "fazer falar" de suas "razões" a "carne" e a "pedra"? Esta é apenas uma coloração da questão mais ampla: como "fazer falar" os artefatos, as coisas? $\mathrm{E}$ ainda: a obra de Sennett faz falar essas coisas? Como?

\section{Modos de expressar}

Os dois rituais femininos da antiga Atenas, com sentidos opostos, tinham em comum o fato de modificarem as condições de presença e pertença da mulher à cidade, ao menos durante o periodo das festividades. É preciso chamar a atenção para o modo como isto era realizado pelas práticas de espaço. Sennett ressalta a operação espacial nos dois casos: nas Tesmofórias, as metonímias do ritual; nas Adônias, um espaço de metáforas. Utilizam-se, portanto, conceitos tomados de empréstimo ao estudo da linguagem, para a compreensão de um modo de fazer espacial.

Quando Michel De Certeau colocava a questão do "como" compreender as práticas sociais, mais especificamente as práticas de espaço, ele lembrava que essas práticas não são apreensíveis diretamente pelos conceitos e representações (1990); as práticas de espaço, quer realizem um plano previamente dado, quer inovem sobre este plano, são silenciosas a respeito delas mesmas, fazem parte de uma dimensão social onde prevalece o nãodito. De Certeau lembrava que, se fosse possivel trazer de volta a experiência grega da métis, seria ao estudo das práticas sociais que ela auxiliaria: razão prática, indícios de ocasião, que norteiam os atos antes mesmo que se tenha refletido sobre eles. Do mesmo modo, Henri Lefebvre (1973), em seus estudos sobre o espaço social, esforçou-se por trazer à luz as três dimensões absolutamente indissociáveis do espaço - práticas, concepções, vivências - para articular as nuances desta relação direta do corpo e da pedra, substrato da experiência do espaço social. 
Michel De Certeau escolheu traduzir uma tal experiência da inteligência como ardil, na referência a um conceito ligado à atividade do poeta e do orador, e por isso, à enunciação em linguagem: a retórica das práticas, uma imagem também lingüística, tanto quanto a metáfora e a metonímia. Isto quer dizer que, se há uma analogia a ser feita entre o uso do espaço social e o discurso, esta analogia deve realizar-se no nível da formação dos discursos, mais que no nível da "sintaxe" dos enunciados. A metonímia amplia o sentido da compreensão de um enunciado dado; a metáfora modifica o seu sentido pela adição de elementos. Assim, nas Tesmofórias, a aceitação social da frieza e do silêncio do corpo feminino tem como resultante a transferência de estatuto: as mulheres citadinas (asté) passam do pólo negativo ao pólo positivo em termos de status, graças às forças de um rifual que usa o espaço urbano de forma determinante para a própria troca do sentido. Nas Adônias, um outro signo aliado à aparição social do gênero feminino se embaralha com práticas espaciais que, a princípio, "não têm sentido": corpo frio, espaço doméstico e reprodução unem-se à mitologia de Adônis, ao discurso feminino, ao espaço do terraço no calor do verão, para dar um sentido inusitado ao gênero feminino, nem positivo nem negativo, simplesmente suspeito, de uma suspeita que, pela estranheza dos sinais mobilizados no ritual, não chega a classificáto como forma de "ameaça à ordem". As Tesmofórias produzem uma mulher dignificada nos valores masculinos da cidade que, por isso, compreende-se como cidadã virtual, em termos políticos. As Adônias produzem a diferença da mulher em um uso inusitado do espaço urbano, trazendo à luz a descontinuidade da ideologia masculina com relação a esse espaço, ou a não correspondência entre o "uso adequado" e as práticas do ritual. O "riso dos oprimidos"? Talvez, como lembra Sennett ao parafrasear John Winkler (1990).

Um paradigma da enunciação discursiva é, pois, a matriz da análise dos rituais femininos na Grécia. Pode-se afirmar que o "uso do espaço" é capaz de uma forma de "enunciação" não discursiva, agenciando gestos, gostos, vozes, toques, olhares? Que as interações sociais têm "razões" que nem sempre podem ser percebidas pelo encadeamento dos discursos, eis um fato. Isto não quer dizer que elas "escapam" ao discurso, mas simplesmente que não há meio de compreendê-las nesta dimensão - do encontro, do corpo e do espaço - a não ser tomando a formação dos discursos como expressão de experiências que envolvem o indivíduo na confluência de seus alos, de seu éthos, de seu páthos.

Estas afirmações nos levam em direção a estudos que têm títulos bastante sugestivos: The silent language e The hidden dimension (1990a; $\mathrm{b})$, de Edward T. Hall. Escritos com o objetivo de auxiliar os diplomatas americanos em seu approach a outras culturas, esses estudos tem o mérito de inaugurar a problemática da proxemística, que pode ser resumida como a análise da dimensão espacial das interações sociais.

\footnotetext{
"The title (The silent languagel summarizes not only the content of the book, but one of the great paradoxes of culture (...). Those of us of European heritage live in a 'word world' which we think is real, but just because we talk doesn't mean the rest of what we communicale with our behavior is not equally important. (...) mankind must eventually come to grips with the reality of other cultural systems and the pervasive effect these other systems exert on how the world is perceived, how the self is experienced, and how life itself is organized" (Hall 1990a: Introduction).
} 
Na perspectiva de Edward Hall, a proxemística seria a ciência capaz de analisar a forma como o sistema cultural de produção do espaço incide sobre os modos de comportamento. Esta relação entre espacialidade e comportamento é uma das primeiras formulações do problema, envolvendo descontinuidade entre discursos e práticas sociais: o que é dito nem sempre corresponde aos índices espaciais do comportamento social. Não me cabe aqui uma abordagem mais detida sobre os objetivos de Hall. Meu interesse é o de analisar, com o auxílio não dos métodos, mas da noção de proxemística, o modo como Richard Sennett percebe a confluência entre práticas sociais, práticas corporais, práticas espaciais nos diversos momentos de seu estudo. Precisamos, para isso, admitir uma das premissas do conceito de proxemística, a saber, que a linguagem silenciosa do espaço é uma forma de comunicação social.

Em todos os capítulos de Flesh and stone esta premissa perpassa a análise de corpo e cidade. Pode-se indicar, por exemplo, como o jogo do próximo e do longínquo no uso do espaço em perspectiva traduz o conflito entre - comportamento modulado pela compaixão cristã e a agressividade do mercador, nas obras de arte já mencionadas acima: A procissão do Calvário, Flagelo e paisagem com a queda de lcaro (Each man is a devil to himself, p.20711). Ou como a organização espacial dos festivais révolucionários na Paris dos séculos XVIII-XIX procurava operar espacialmente pela criação, no corpo do cidadão, de um sentimento de conexão mútua, e conexão com a nova pátria (The body set free, p. 304-101.

Assim também na Roma de Adriano, a cidade de Roma no começo do século Il d.C., centro de um Império em inflexão (The obsessive image, p.87-123), uma imagem obsessiva da geometria do corpo presidia a concepção do espaço, desde os espaços públicos até as casas particulares. O edifício do Panteão reconstruído por Adriano é o ponto de partida de um estudo que se pergunta de que forma as edificações romanas forjavam o "convite" a olhar e acreditar, olhar e obedecer, mantendo a suspensão do tempo e do espaço do império na imagem da Roma eterna.

A visualização do poder e da força de Roma apoiava-se na necessidade de se experimentar sensorialmente o espaço, o tempo, o mundo, e, nessa sensorialidade, estruturar a garantia de continuidade. Uma "linguagem do espaço" operava então, dirigindo a experiência da visão: olhar e acreditar. Assim como os rituais femininos na Grécia transformavam o estatuto da mulher pelas metáforas e metonímias do espaço, rituais romanos agiam no dia a dia das relações sociais, operando no sentido de fazer crer na Roma eterna, a cidade do Lácio, principalmente numa época em que o encontro diário da vida na cidade poderia dissolver a crença nessa imutabilidade. Sennett observa que Roma celebrava-se como um theatrum mundi, do qual o plano do Panteão criava um microcosmo.

\footnotetext{
"the ideal of an essential and continuing Rome was a necessary fiction for Romans (...). However, simply asserting that city was 'Eternal' would hardly suffice (...) To make fiction of an 'Eternal City' credible, the emperor had to dramatize his powers in a certain way, and the people had to treat city life as a kind of theatrical experience" (p.96).
}

Estas palavras de Sennett demonstram o sentido da busca pela linguagem do espaço, na experiência do corpo: trata-se de uma dimensão cuja eficácia nos agenciamentos de poder, de status, de hegemonia social e imperial, 
é crucial para a manutenção do Império. Esta eficácia é dada por uma determinada forma de agir: a dramatização. Mais que as apologias ou as palavras ditas, um espaço como o do Panteão, um ritual de fundação constantemente repetido para as novas cidades em todas as partes do Império (estabelecimento inicial do mundus para o traçado das cidades), as imagens cotidianas e as festas (como os combates de gladiadores; o "circo"), realizavam sua tarefa de conexão em prol de um stałus quo através da realização de imagens repetidás, do gestual, da pantomima do poder. Uma mimese que precisa do olhar, que precisa atrair pelos sentidos, principalmente pela visão. Uma mimese cujo combate está no centro da questão do arrebatamento do império pela nova religião: o cristianismo (Time in the body, p. 124-50). A história da Roma de Adriano pode ser contada pelas práticas de espaço, como a história de um universo em que o poder precisa da mimese, no sentido da concretude da ficção. Os primeiros cristãos vão opor sua peregrinação no espaço, e sua história do tempo da redenção, à mimese do poder imperial. Duas linguagens opostas do espaço convidam a duas experiências antagônicas do "si mesmo", do "corpo", e do "convivio".

A retórica das práticas do espaço, o espaço da dramatização, ambos apontam para a relação entre espacialidade e significado, ou significação, uma significação agenciada pelo corpo, na direção do corpo. Em um dos capítulos de Flesch and stone, Sennett sintetiza esta perspectiva em um plano geral:

"resistance is a fundamental and necessary experience for the human body: through feeling resistance, the body is roused to take note of the world in which it lives. This is the secular version of the lesson of the exile from the Garden. The body comes to life when coping with difficulty" (The body set free, p. 310 ).

Minha sugestão é a de que o trecho seja compreendido literalmente: através da resistência, o corpo é despertado para tomar nota do mundo em que vive; através dessa experiência se produzem historicamente determinadas compreensões do corpo, e determinadas configurações do espaço. Portanto, o mundo "em que se vive" comunica.

Deste modo é possivel compreender a neutralidade do espaço e a passividade do corpo na cidade moderna. No último capítulo de Flesch and stone, Sennett procura fazer uma análise dos desencontros sociais na Nova York multicultural, em que a diversidade se justapõe à indiferença (Civic bodies, p.355-76). Para que a presença de diferença e indiferença se articulem em Nova York, é preciso que se compreenda, diz Sennett, o modo como os "encontros" com o diferente acontecem nas ruas da cidade. Uma espécie de "snapshot" mental ou reação imediata se processa nessas ocasiões, coordenando as relações entre pessoas, e a percepção do espaço urbano. Um motorista que atravessa a cidade, substituirá o encontro com o lugar imagens do "familiar", do "estranho", etc., que guarda consigo em um "repertório" socialmente produzido:

"Scanning a complex or unfamiliar scene, the individual tries to sort it out rapidly in terms of images which fall into simple and general categories, drawing on social stereotypes. $(\ldots)$ The judgement $(\ldots)$ is instant and result surprising; thanks to the classifying powers of the image repertoire, people shut out further stimulation. Confronted with difference, they quickly become passive (...) (p.365). 
repertório de imagens participa da noção de um sentido não totalmente verbalizado nem concebido das relações sociais. Não é preciso reinterpretar sempre o conjunto de representações sociais que constróem 0 "estrangeiro", por exemplo, para concluir, em um encontro casual, que não se deve othar para um deles em demasia; assim como não é preciso elaborar a cada momento as conseqüências culturais do uso de saias para compreender que "saias são femininas". A forma de apaziguamento do encontro do corpo com a pedra que se produz pelo "snapshot", indica que aquilo a que se procura ater no encontro não é nem ao corpo, nem à pedra, que são ambos produzidos no encontro; é o meio, o intermediário que se pretende discernir com recurso aos termos "snapshot", ou "repertório de imagens", metonímias e metáforas rituais. Neste caso específico, o intermediário ou o operador do encontro é um sistema de classificações; uma "gramática" baseada em imagens, utilizada na prática cotidiana do espaço da cidade. Nesta prática, os objetos no mundo experimentado atualizam determinadas requisiçōes sociais, determinados significados. Os artefatos, como o espaço, tomados como agenciadores de sentido, como "enunciadores", conduzem as abordagens de Sennett em direção àquilo que Marshall Sahlins chamava, já há algum tempo, uma lógica significativa do concreto (1977).

\section{N. $\bigcirc$ artefato}

Incidir sobre o corpo e o espaço significa tomar a experiência humana no limiar de sua materialidade. É preciso compreender que, nessa materialidade, o estudo do artefato deve se colocar em questão; é preciso, enfim, discutir as implicações dessa compreensão diante de uma história humana, de uma história social.

Não pretendo considerar aqui todo o debate sobre conceitos e formas de abordagem da cultura material. É suficiente, para isso, citar alguns estudos como as obras-sínteses editadas por Thomas J. Schlereth (1985), e Susan Pearce (1990), o livro Culture and consumption (McCracken 1988), o próprio Marshall Sahlins em seu Culture and practical reason (1977). Trata-se, basicamente, de superar a oposição entre material e imaterial para que a "coisa" possa ser inserida em sua real dimensão de eficácia cultural. Se se mantém o abismo entre subjetivo e objetivo, o universo da cultura material será sempre tributário das concepções; ou as concepções serão desconsideradas no estudo dos objetos. Se a problemática em torno da cultura material deve tomar o artefato como "produto e vetor de relações sociais" (Meneses 1983), isto significa que a produção, circulação, uso, organização das "coisas" comunica algo, organiza, em sua dimensão, todo um campo silencioso das interações sociais. Por isso, conceitos como os de signo, símbolo, ícone, estão no centro das abordagens da cultura material nos autores que citei.

"The object does not, indeed cannot, exist without an interaction with someone. In order to create a sign, which is a physical unitof-meaning (physical because it is encoded in a sound, a vision, a touch, a smell, a taste) there must be some action of a human being which makes this physical unit into a sign, a unit of social meaning. And then it must be used, interacted with, in order to be existent as a unit-of-meaning" (Taborsky 1990: 57). 
Edwina Taborsky propõe que, no paradigma discursivo aplicado à cultura material, o objeto não existe senão como realidade material num contexto de interação; por isso a autora marca a necessidade de se considerar o uso, pois somente nele o objeto se produz como unidade-de-significado. Afirma ainda que - objeto é unidade-de-significado na dimensão material, no momento de sua percepção em sons, olhares, toques, cheiros, gostos. Isto constitui a experiência humana; e o trecho de E. Taborsky se insere na discussão do modo como se define a importância do artefato na produção desta experiência.

Como o próprio Sennett declara na introdução de Flesch and stone, seu livro pretende ser um ensaio composto por um dedicated amateur (p. 23). Mas na liberdade que 0 "amadorismo" Ihe permite, a questão do artefato na formação da experiência humana está sempre presente. $O$ fato de se ressaltar a carne, a pedra, significa uma tentativa de alcançar a superfície permeável do toque, nesse encontro gerador de objetividade, de subjetividade, de ambiente. Nessa tentativa, a coisa é tomada nessa pespectiva mais atual a que me referi acima: produfo e vetor, unidade de sentido na dimensão material da vida social.

Um ideal muito concreto na França revolucionária

Consideremos a figura de Marianne (The body set free, p.282-316). Richard Sennett procura demonstrar que uma determinada concepção do corpo feminino produzia esta imagem, na iconografia como na estatuária. Esta concepção era a de um corpo materno, propondo-se a doar livremente o seu leite, e a conectar, assim, os novos cidadãos oriundos da Revolução:

"The lactating breast of Marianne most of all suggested that fraternity was a sensale bodily experience rather than an abstraction. (...) The act of breast feeding became in the revolutionary broadsheet an image of mutual arousal - between mother and child, government and the people, citizens among themselves" (p.291).

Mas como conciliar a expressão de um corpo incondicionalmente doador como o de Marianne, a procura do contato que este corpo promovia, com a liberdade concebida espacialmente com a criação de volumes vazios, sem obstáculos, como pretendem as tendências de organização dos espaços urbanos (p.292-93)? O questionamento deste paradoxo procura sempre a dimensão material do ideal revolucionário de liberdade, igualdade, fraternidade. Fraternidade no corpo, diz Sennett, conflita com a liberdade no espaço; explicação da extrema dificuldade da Revolução em encontrar um lugar para dispor Marianne.

"The vision of fraternity in human relations expressed itself as flesh touching flesh; the vision of freedom in space and time expressed itself as empty volume" (p.296).

Com isso, o valor humano que deveria pautar o novo cidadão acaba por encontrar, em seus destinatários - os homens e mulheres do "povo" - a passividade expressa numa atitude corporal: não se vê, não se ouve, não se toca, enfim, não se experimenta no corpo o despontar da nova época que a Revolução pretende inaugurar. Na expressão física de dois dos ideais - liberdade, 
fraternidade - o conflito promove a pacificação do corpo revolucionário. Mas este conflito é sentido, literalmente, no encontro da carne com a pedra, e é neste encontro que a Revolução pode produzir uma estratégia não totalmente racionalizada, de apaziguamento do corpo pela prática do espaço.

Marianne é expressão de um imaginário, em que o corpo feminino relaciona-se, por oposição aos corpos erotizados do Antigo Regime, aos cuidados da maternidade. A iconografia de Marianne não é analisada como uma construção de símbolos remetendo a certos ideais exteriores, mas como expressão física desses ideais: é na dimensão física que a Revolução produz o conflito. É neste sentido que a imagem veiculada de Marianne substancia uma nova experiência do corpo; e nessa nova experiência do corpo a possibilidade de uma nova compreensão das relações humanas. "Espaço" emerge, portanto, como artefato: produto da "Revolução", mas ao mesmo tempo agente na produção dos corpos passivos, e co-protudor do individualismo moderno - direito de não ser tocado, nem pelo corpo, nem pelas palavras de outrem.

Não por acaso, Senneft responsabiliza uma "macro-individualidade" designada pelo nome geral 'de "Revolução" pelas estratégias que se contradizem: o corpo doador, o espaço vazio, acarretando a pacificação e o alheamento do cidadão por atitudes corporais. Essa generalização não significa nem o apelo à pura abstração, nem a referência às "classes dirigentes". A individualidade da "Revolução" reúne em um só termo a inspiração revolucionária, seus ideais e sua filosofia, a sua divulgação e propaganda, assim como a sua prática; reúne o conjunto de seus líderes, de seus idealizadores, planejadores, ao povo de Paris diante da imagem fraterna e doadora de Marianne, participando dos festivais revolucionários e das execuções pela guilhotina; conjuga o produto e a produção, e traduz, assim, um circuito cultural que alimenta a reconstrução física e moral do cidadão em termos modernos - o individuo livre em uma cidade sem obstáculos ào movimento.

Uma cadeira

Para dar a compreender a postura do corpo própria ao indivíduo moderno, Richard Sennett analisa a produção das "poltronas confortáveis" (comfortables) no século XIX (Urban individualism, p.338-43). Trata-se de questionar o modo como essas poltronas testemunham uma nova postura do sentar-se, correspondendo a uma experiência do corpo e do convívio bastante recente na civilização ocidental. O conforto dos assentos estofados, visava ao corpo "em fadiga"; mas era também um descanso dos outros:

"Nineteenth-century chairs subtly but powerfully changed this experience of sitting sociably; they did so thanks to innovations in upholstery $(\ldots)$. Comfort in these chairs came to imply a particular kind of human posture (...) "based on relaxation in a free, unposed attitude that can be called neither sitting, nor lying" " (p.340)

Graças a uma inovação técnica na produção de assentos, a um novo design baseado na valorização dos estofados, muda a experiência de sentar-se socialmente no século XIX. É interessante notar como uma determinada modulação do artefato pode ser chamada a testemunhar na mudança de postura do corpo, uma mudança que é parte integrante da formação do moderno individualismo. $O$ 
assento confortável faz isso de forma sutil, não percebida, e por isto mesmo poderosamente. Podemos compreender essas afirmações como uma forma de dizer que a configuração de um novo universo material, que certamente não se promove ex machina, participa na transformação das formas como os indivíduos interagem nas situações sociais. A interpretação correla, neste caso, deve passar pela questão: o projeto da cadeira confortável é o responsável pela postura le então retornaríamos à concepçãol? Mas talvez o abismo entre o concebido diretamente em relação a um artefato e o uso deste artefato nas ocasiões seja bastante grande; ou então seja tão próximo quanto o são todas as dimensões da realidade social - práticas, concepções, vivências - de modo que a linguagem do objeto fala em seu mundo, a partir de todos os outros, numa perspectiva da qual só ela pode falar. Estudar o molde de um artefato como a cadeira confortável, é também inquirir sobre a experiência humana do corpo e do espaço que o produziv e foi por ele re-produzida.

A abordagem do artefato em. Flesch and stone é uma tentativa bem sucedida de "fazer falar" a coisa, na produção de uma história social. Pode-se, por isso, situar essa abordagem como a da história de uma interação, mais do que uma história de seus produtos. Mas o que está no meio, entre a "carne" e a "pedra", superfícies de experimentação, ao mesmo tempo infinitamente distintas, independentes? A razão prática, ou a lógica do concreto, preconizadas por Marshall Sahlins (1977), a textualidade do universo material, de Edwina Taborsky (1990), a linguagem silenciosa, de Edward T. Hall (1990a), a retórica das práticas (De Certeau 1990), todos exemplos de estudos que subentendem o paradigma do artefato como instrumentalizador de um discurso das coisas, e, portanto, de comunicação social (não confundir com coesão social). A obra de Sennett, sem se referir a estudos teóricos em particular, incide sobre um tema cuja possibilidade de abordagem, até pouco tempo, estaríamos discutindo. Afinal, não é a dimensão da experiência por demais subjetiva? As práticas de espaço excessivamente "espontâneas"? Não nos arriscamos, ao tomar as "coisas" como vetores de um discurso social, a "desmanchá-las no ar"?

Creio ter demonstrado suficientemente que a proposta de Sennett desafia e ultrapassa essas questões. Flesch and stone deixa claro o ponto de vista de que a experiência humana não apenas conjuga corpo e espaço, mas não pode prescindir deste mútuo choque que a constitui. Neste choque, nem corpo, nem espaço, podem ser pacientes. Ao contrário, são agentes: o corpo sente o espaço, o espaço "promove" o corpo; nem corpo nem espaço podem ser compreendidos como "dons" naturais, muito menos blocos isolados. O que trespassa as linhas do livro de Richard Sennett é a imersão das "concepções", com as quais se procura organizar o "mundo" como "lugar" de homens e "lugar" de coisas, no percebido e vivido (i)mediato, ou seja, naquilo que deve ser compreendido como a dimensão material da vida social. O livro de Sennett nos oferece, portanto, uma oportunidade para refletir sobre um bom exemplo de análise, que agencia testemunhos pessoais, tratados científicos, planejamentos espaciais, obras de arte, abjetos, enfim, para possibilitar uma história da produção material da sociedade e do indivíduo, através da prática espacial e da experiência corporal que se conjugam nas interações sociais. 


\section{BIBLIOGRAFIA CITADA}

AUSTIN, M. \& VIDAL-NAQUET, P. Économie et Société en Grèce Ancienne. Paris: Armand Colin, 1972.

BRAUDEL, Fernand. Civilisation matérielle et capitalisme. v.1. Le possible et l'impossible: les hommes face à leur vie quotidienne. Paris: Armand Colin, 1967.

DE CERTEAU, Michel. L'Invention du quotidien: Arts de Faire. Paris: Gallimard-Folio, 1990. v.1.

DETIENNE, Marcel \& VERNANT, Jean-Pierre. Les ruses de L'inteligence: la métis des Grecs. Paris: Flammarion, 1976.

FOUCAULT, Michel. Surveiller et punir. Paris: Gallimard, 1975.

FOUCAULT, Michel. La Gouvernementalité (1978). Inutile de se soulever? (1979) In: Dits et écrits. Paris: Gallimard, 1994, v.3, p. 635-57, 790-94.

HALL, Edward T. The silent language. New York: Doubleday, 1990a.

HALL, Edward T. The bidden dimension. New York: Doubleday, $1990 \mathrm{~b}$.

JACOB, François. La logique du vivant. Paris: Gallimard, 1970.

LEFEBVRE, Henri. La production de l'espace. Paris: Anthropos, 1973.

LORAUX, Nicole. Les enfants d'Athna: idées Athéniennes sur la citoyenneté et la division des sexes. Paris: La Découverte, 1990.

MCCRACKEN, G. Culture and consumption: new approaches to the symbolic character of consumer goods and activities. Bloomington: Indiana University Press, 1988.

MENESES, Ulpiano B. de. "A cultura material no estudo das sociedades antigas". Revista de História, n.115, p.103-17, jul./dez. 1983.

SAHLINS, M. Culture and practical reason. Chicago: University of Chicago Press, 1977.

SCHLERETH, Thomas. Material Culture: a research guide. Lawrence: University of Kansas Press, 1985.

SENNETT, Richard. The fall of public man. Cambridge: Cambridge University Press, 1974.

SENNETT, Richard. The conscience of the eye: the design and social life of cities. New York: A.Knopft, 1990.

SENNETT, Richard, ed. Classic essays on the culture of cities. New York: Appleton-Century-Crofts, 1969.

TABORSKY, Edwina. "The discursive object". In: PEARCE, Susan (Ed.) Objects of knowledge. London: Athlone, 1990. p.50-77.

WINKLER, John. The Constraints of Desire: the Anthropology of sex and gender in Ancient Greece. New York: Routledge, Chapman \& Hall, 1990.

ZEITLIN, Froma. Playing the Other: gender and society in classical Greek literature. Chicago: University of Chicago Press, 1996. 
Psicologia Social e Cultura Material

Ulpiano T. Bezerra de Meneses

O A. avalia a contribuição de Helga Dittmar em The Psychology of material possessions. To have is to be, ao estudo psicológico da cultura material. Apresenta-se rapidamente um histórico da pesquisa sobre as posses materiais como um "eu estendido". A despeito da utilidade do livro como um repositório de informações de todo tipo, esta não é ainda a obra de síntese, tão necessária, sobre o potencial da Psicologia Social no estudo da cultura material, em virtude das muitas lacunas, assim como de um tratamento superficial e enciclopédico de várias questōes-chave.

UNITERMOS: Cultura Material. Posses materiais. Psicologia Social.

Anais do Museu Paulista, N.Sér, v.4, p.283-90, jan./dez.1996

Social Psychology and Material Culture

Ulpiano T. Bezerra de Meneses

The A. appraises Helga Dittmar's contribution to the psychological understanding of material culture (The Psychology of material possessions. To have is to bel. A short historical background is given for the study of material possessions operating as an "extended self". In spite of its usefulness as a repertoire of information of all kinds, Dittmar's book is not yet the much needed synthesis of Social Psychology's potential for a deeper knowledge of material culture, due to several gaps as well as to the cursory and encyclopaedic treatment of many central issues.

UNITERMS: Material Culture. Material possessions. Social Psychology.

Anais do Museu Paulista, N.Sér. v.4, p.283-90, jan./dez.1996

Prática do espaço, experiência do corpo: Sennett e a cidade

Marta Mega de Andrade

Este ensaio tem por eixo a obra de Richard Sennett, Flesh and stone. The body and the cily in Western civilization. Salienta algumas questöes centrais na obra de Sennett: a relação entre a história global e a perspectiva local; os usos ou "formas de fazer como formas de produzir". Embora não seja preocupação central de Sennett, são investigadas implicações destas questões no campo dos estudos da cultura material, especialmente a possibilidade de um paradigma discursivo na análise espacial das práticas corporais.

UNITERMOS: História Urbana. História do corpo. Corpo e espaço.

Anais do Museu Paulista, N.Sér. v.4, p.291-308, jan./dez.1996

Spatial practices and bodily experience: Sennett and the city

Marta Mega de Andrade

This essay focuses on Richard Sennett's Flesh and stone. The body and the cily in Western civilization. It stresses some of the central questions in Sennett's book: the relationship between a global history and a local perspective; "uses" or "ways of doing" as ways of producing. Although not Sennett's main concern, implications of these questions in the field of material culture studies are investigated, especially the possibility of a discursive paradigm in the analysis of spatial practices and bodily experiences.

UNITERMS: Urban History. History of the body. Body and space

Anais do Museu Paulista, N.Sér. v.4, p.291-308, jan./dez.1996 